\title{
Why we reject papers with calculations of inhibitor adsorption based on data on protective effects
}

\section{Dear colleagues,}

We have been issuing our journal for almost three years. Now it seems a right time to summarize some results. They are positive in general, but with some reservations.

The Journal has a fair number of readers. It has increased to 200-250 persons per month. It is a very good result for a specialized scientific journal. Still, the circle of readers continues to grow.

The number of contributors is also increasing. During the three years that the journal exists, we have published over 70 papers dealing with various theoretical and practical aspects of inhibitory protection of metals. However, the number of publications might have been about $15 \%$ larger. Some manuscripts have been rejected by our reviewers. Let us analyze them in more detail.

In most cases, manuscripts are rejected for the same reason: they contain calculations of metal surface coverage by an inhibitor based on data on inhibitor protective effects $(Z)$.

Why should this not be done without a special justification or at least assumptions? The answers to this questions have been given more than half a century ago and unfortunately have been forgotten by many researchers. We feel it appropriate to remind the readers about some concepts of the theory of inhibitor action.

In the manuscripts that we had to reject, the values of surface coverage by an inhibitor $(\Theta)$ were calculated from so-called kinetic data, i.e., in essence, they were identified with the degrees of protection:

$$
\Theta=1-\left(i_{\text {inh }} / i\right)=Z
$$

or

$$
\Theta=1-\left(k_{\text {inh }} / k\right)=Z,
$$

where $i$ and $i_{\text {inh }}$ are the current densities of metal dissolution in the absence and in the presence of an inhibitor in the corrosive electrolyte, respectively, while the $k$ values are the corrosion rates with similar designations.

Derivation of these equations is easy but involves important assumptions [1]. Let us assume that inhibitor adsorption does not affect the metal dissolution kinetics on the surface not covered by the inhibitor. In such case, the surface covered by the inhibitor is characterized by the current density of metal dissolution $i_{\Theta=1}$ and the free surface is characterized by the current density $i_{\Theta=0}$. Then the total metal dissolution current density can be represented as:

$$
i_{\text {inh }}=i_{\Theta=1} \Theta+i_{\Theta=0}(1-\Theta)
$$


In those cases where the inhibitor totally prevents metal dissolution from the covered surface, i.e., where $i_{\Theta=1}=0$, Equation (3) can be transformed to Equation (1), and if the inhibitor does not affect the corrosion potential, to Equation (2).

Thus, Equations (1) and (2) can be used for inhibitors of purely blocking type that act just by surface screening. For blocking inhibitors, and only for them, the $Z$ and $\Theta$ values are equal. A criterion of the blocking mechanism is that the inhibitor does not affect the effective activation energy of the anodic process.

If this condition is not met, it is absolutely prohibited to use the $i$ or $k$ values for estimation of $\Theta$.

It should be noted that blocking inhibitors occur very rarely $[2,3]$. Inhibitors of activation and mixed type are much more common. Activation-type inhibitors affect the activation energy of the corrosion process but do not possess a screening effect. Inhibitors of mixed type include the majority of organic compounds. In the latter case, the screening effect is added to the activation effect.

It is important that in some of the manuscripts that we rejected for the reasons described above, the effective activation energy of corrosion was estimated and its variation upon inhibitor addition was observed. Still, this fact did not prevent the authors from using Equations (1) and/or (2).

Determination of adsorption is one of the most important aspects in the studies on the mechanism of action of corrosion inhibitors. It cannot be skipped in any serious work on this subject. However, as one of the founders of inhibitor science wrote, "determination of $\Theta$ from corrosion rate cannot provide anything new for understanding of the corrosion mechanism" [3].

\section{References}

1. I. L. Rozenfel'd, Ingibitory korrozii (Corrosion inhibitors), 1977, Moscow, Khimiya (in Russian).

2. V.P. Grigor'ev and V. V. Ekilik, Khimicheskaya struktura i zashchitnoe deistvie ingibitorov korrozii (Chemical structure and protective effect of corrosion inhibitors), Rostov-on-Don, Rostov University Publishing House, 1978 (in Russian).

3. L. I. Antropov, E. M. Makushin and V. F. Panasenko, Ingibitory korrozii metallov (Metal Corrosion Inhibitors), Kiev, Tekhnika, 1981 (in Russian).

From the Editorial Board: Yu. I. Kuznetsov, N. N. Andreev and S. S. Vesely 